\title{
Multifactorial evaluation and treatment of persons with a high risk of recurrent falling was not cost-effective
}

\author{
G. M. E. E. Peeters • M. W. Heymans • O. J. de Vries • \\ L. M. Bouter $\cdot$ P. Lips $\cdot$ M. W. van Tulder
}

Received: 26 April 2010 /Accepted: 15 September 2010 /Published online: 20 October 2010

(C) The Author(s) 2010. This article is published with open access at Springerlink.com

\begin{abstract}
Summary This study evaluated the cost-effectiveness of multifactorial evaluation and treatment of fall risk factors in community-dwelling older persons at high risk of falling. The intervention and usual care groups did not differ in fall risk or costs. The multifactorial approach was not costeffective compared to usual care in this group.

Introduction International guidelines recommend multifactorial evaluation and tailored treatment of risk factors to
\end{abstract}

G. M. E. E. Peeters $\cdot$ M. W. Heymans $\cdot$ P. Lips $\cdot$ M. W. van Tulder Department of Epidemiology and Biostatistics, EMGO Institute for Health and Care Research, VU University Medical Center, Amsterdam, The Netherlands

M. W. Heymans

Department of Methodology and Applied Biostatistics,

VU University Amsterdam,

Amsterdam, The Netherlands

O. J. de Vries

Department of Internal Medicine, Section Geriatrics,

VU University Medical Center,

Amsterdam, The Netherlands

L. M. Bouter

Executive Board, VU University Amsterdam,

Amsterdam, The Netherlands

\section{P. Lips $(\bowtie)$}

Department of Internal Medicine, Section Endocrinology,

VU University Medical Center,

Postbus 7057, 1007 MB Amsterdam, The Netherlands

e-mail: p.lips@vumc.nl

\section{W. van Tulder}

Department of Health Sciences, Faculty of Earth and Life,

VU University Amsterdam,

Amsterdam, The Netherlands reduce falling in older persons. The cost-effectiveness may be enhanced in high-risk persons. Our study evaluates the cost-effectiveness of multifactorial evaluation and treatment of fall risk factors in community-dwelling older persons at high risk of recurrent falling.

Methods An economic evaluation was conducted alongside a randomised controlled trial. Participants ( $\geq 65$ years) with a high risk of recurrent falling were randomised into an intervention $(n=106)$ and usual care group ( $n=111)$. The intervention consisted of multifactorial assessment and treatment of fall risk factors. Clinical outcomes were proportions of fallers and utility during 1 year. Costs were measured using questionnaires at 3, 6 and 12 months after baseline and valued using cost prices, if available, and guideline prices. Differences in costs and cost-effectiveness were analysed using bootstrapping. Cost-effectiveness planes and acceptability curves were presented.

Results During 1 year, 52\% and 56\% of intervention and usual care participants reported at least one fall, respectively. The clinical outcome measures did not differ between the two groups. The mean costs were Euro 7,740 (SD 9,129) in the intervention group and Euro 6,838 (SD 8,623) in the usual care group (mean difference Euro 902, bootstrapped $95 \%$ CI: $-1,534$ to 3,357). Cost-effectiveness planes and acceptability curves indicated that multifactorial evaluation and treatment of fall risk factors was not cost-effective compared with usual care.

Conclusions Multifactorial evaluation and treatment of persons with a high risk of recurrent falling was not costeffective compared to usual care.

Keywords Accidental falls · Cost-effectiveness · Multifactorial intervention P Prevention 


\section{Introduction}

Fall incidents are the third cause of chronic disability in older persons according to the WHO [1]. One in three community-dwelling persons of 65 years and older falls once per year [2-4] and about $25 \%$ of the fallers consult the general practitioner or Accidents and Emergency (A\&E) department of a hospital $[5,6]$. The consequences may be severe and approximately $5 \%$ of the falls result in a fracture [6]. In older persons consulting the A\&E department after a fall, the average total costs from the moment of the fall to 1 year later have been estimated at Euro 4,991 [7]. Because of the increasing number of older persons in the next decades, the number of fallers is expected to rise. Preventive measures are needed to reduce the number of falls and related costs. Although many trials have evaluated the effectiveness of preventive interventions, few have evaluated the cost-effectiveness of these interventions.

Over the past decade, many randomised controlled trials (RCTs) have studied the effectiveness of multifactorial interventions, i.e. multifactorial evaluation and treatment of fall risk factors [8-16]. Despite conflicting results among original trials, meta-analyses seem to favour multifactorial interventions [17-19]. Although the evidence does not seem to be conclusive, international guidelines recommend multifactorial evaluation and tailored treatment of fall risk factors $[20,21]$. Increasing numbers of geriatricians initiate fall prevention programs based on these guidelines. Given the large number of fallers, evaluation and treatment of every older person after a fall is not feasible. It may be more cost-effective to limit the intervention to older persons with the highest fall risk [22].

To our knowledge, only two studies have focused on the cost-effectiveness of multifactorial interventions among community-dwelling older persons. The first study was conducted in the US and found that the intervention was more cost-effective than usual care and this effect was the largest in the high risk group [23]. The second study found that the evaluation of fall risk factors by a geriatrician and occupational therapist was not cost-effective as compared with usual care in The Netherlands [7]. However, the first study did not include patient costs (e.g. informal care and self acquired aids and adaptations), and in the second study, the compliance rate was low and the patients were not screened for fall risk [24].

Our study aims to evaluate the cost-effectiveness of multifactorial evaluation and treatment of fall risk factors compared to usual care in community-dwelling older persons at high risk of recurrent falling. The economic evaluation is conducted from a societal perspective. The effectiveness of this intervention has been described in detail elsewhere [25]. Although the intervention did not reduce the fall risk as compared with usual care, we believe it is important to evaluate the costs in both groups because of three reasons. First, the intervention may have reduced the severity of the consequences of new falls and, on the long term, may be cost-saving compared to usual care. Second, if the intervention is associated with higher costs than usual care, this would be an argument not to implement the intervention. This is particularly important because fall prevention programs are becoming increasingly more popular in The Netherlands and other countries. Third, to avoid publication bias, it is important to publish results from all economic evaluations regardless of their results. If only "positive" results would be published, policy makers would use misleading information and policy decisions would be invalid.

\section{Methods}

The study was designed as an economic evaluation alongside a RCT. The design of this study was described in detail elsewhere [26]. This paragraph summarizes the details that are relevant for this paper.

\section{Study population}

The study population consisted of persons of 65 years and older who consulted their general practitioner or the A\&E department of the VU University Medical Center, Amsterdam, The Netherlands, after a fall accident between April 2005 and July 2007. Inclusion criteria were living independently or in a residential home, living in the vicinity of the VU University Medical Center and having experienced a fall less than 3 months ago. Exclusion criteria were inability to sign informed consent, inability to provide a detailed history and scoring less than 24 points on the MiniMental State Examination, fall due to a traffic or occupational accident, living in a nursing home and acute pathology requiring long-term rehabilitation such as a stroke. During the first home visit within 3 months after the presenting fall, the risk of recurrent falling was assessed using the validated LASA fall risk profile [27, 28]. This risk profile consists of the following nine items: two or more falls in the preceding year, regular dizziness, functional limitations, poor grip strength, low body weight, having a cat or dog in the household, fear of falling, high alcohol intake and a high level of education. After the first home visit, 36 participants did not meet the inclusion criteria and were excluded. Participants who scored 7 points or lower on the fall risk profile were considered at low risk of recurrent falling and were excluded from the RCT and economic evaluation. Participants with a risk score of 8 or higher and participants living in a residential home were considered to be at high risk of recurrent falling. These 
high-risk participants were randomly allocated to the intervention and usual care groups. At the end of the home visit, an appointment was made to visit the geriatric outpatient clinic for persons in the intervention group. No extra assessments or visits were done in the usual care group.

\section{Intervention}

The multifactorial transmural intervention started with a visit to the geriatric outpatient clinic. A multifactorial fall risk assessment was conducted by the geriatrician to identify modifiable fall risk factors. The assessment of fall risk factors and the design of the treatment plan were based on the Dutch Institute for Healthcare Improvement (CBO) guideline "Prevention of fall incidents in older persons" [20]. The assessment consisted of a general medical history, a fall and mobility history, and physical examination with special emphasis on signs of postural hypotension, neurological deficits, visual disturbances, gait and mobility disorders and medication. Additional diagnostic tests were performed if indicated (e.g. laboratory tests or imaging). Based on the assessment of fall risk factors, an individually tailored treatment regimen aimed at reduction of the fall risk was composed in collaboration with the general practitioner of the participant. The multifactorial treatment consisted of, for example, withdrawal of psychotropic drugs, balance and strength exercises by a physical therapist, home hazard reduction by an occupational therapist or referral to an ophthalmologist or cardiologist.

\section{Usual care}

During the study period, usual care in The Netherlands after a fall mainly consisted of treatment of the consequences of the fall. Although a national guideline was released in 2004 [20], multifactorial fall risk prevention had not yet been implemented by general practitioners or at the $\mathrm{A} \& \mathrm{E}$ departments.

\section{Clinical outcome measures}

Clinical outcome measures of the economic evaluation were the prevalence of fallers and recurrent fallers and utility (quality of life). All participants reported falls during at least 1 year using a fall calendar [4]. The participants ticked per week whether they did or did not fall. Once per 3 months the participants returned a calendar sheet by mail. When no sheet was received, or when the sheet was completed incorrectly, we inquired by telephone whether and when the participant had fallen in the past 3 months. A fall was defined as an unintentional change in position resulting in coming to rest at a lower level or on the ground
[29]. Recurrent falling was defined as having fallen twice or more within a 6-month period [27].

Utility was assessed at baseline and after 1 year using the EuroQol (EQ-5D) [30]. This questionnaire was developed to generate a general index of experienced health. Health states were estimated using reference values from a representative Dutch sample (range 0, death, to 1, optimal health) [31]. Quality Adjusted Life Years (QALYs) were calculated as the area under the curve, with straight-line interpolation between utility at baseline and 1-year follow-up.

\section{Costs}

The economic evaluation was conducted from a societal perspective. Healthcare costs (e.g. geriatrician consult, general practitioner care, specialist care, therapy, medication, hospitalisation and nursing home admittance), patient and family costs (e.g. informal care), and costs in other sectors (e.g. medical devices, home modifications and transportation aids) were measured during 1 year after baseline (the footnote of Table 4 provides an overview of all cost categories and all items included per category). All health-related costs were taken into account, since it is impossible to distinguish fall-related from non-fall-related costs. Medical interventions undertaken to treat other health problems can directly or indirectly affect the fall risk. For example, someone may visit his GP for a monthly blood pressure measurement and subsequent adjustments in his medication may affect his fall risk. Productivity costs were not included, because all persons were above 65 , the age of retirement in The Netherlands.

The participants received a cost-evaluation questionnaire 3, 6 and 12 months after the first home visit. The 3- and 6months questionnaires were sent by mail, the 12-months questionnaire was assessed by a research assistant during a second home visit 1 year after baseline. Healthcare costs were valued using the Dutch guideline prices published in the "Handbook for cost studies, methods and guidelines for economic evaluation in health care" [32]. This handbook contains prices for, for example, hospital admittance, physiotherapy and general practitioner consultation. The costs of medication use were estimated based on the medicine use reported during the first home visit at baseline and the second home visit after 12 months. Participants were asked which medications (both over the counter and prescribed drugs) they had used during the previous 2 weeks. Generic names and doses were copied directly from the containers. Also, the frequency and dose per intake were reported. Since the number of units taken during the year of follow-up was not known, an estimation was made based on the available information and the following assumptions: (1) medicine for chronic use 
reported at both home visits=frequency $\times 365$ days; $(2)$ medicine for chronic use reported at one home visit $=$ frequency $\times 0.5 \times 365$ days; (3) medicine for temporary use $=$ frequency $\times 0.5 \times$ recommended duration; (4) medicine for incidental use $=10 \%$ from the number of units in case of chronic use and (5) for participants who dropped out before the second home visit, the number of units was estimated based on half the number of days until drop out. In the second, third and fifth assumption, it was unknown how long the participant had been taking a medication on the time point of assessment. Therefore, $0.5 \times$ the expected total duration was believed to be the overall best estimated duration. Information on recommended duration of medications was obtained from the pharmaceutical guidelines published by the Dutch Health Insurance Board (CVZ) [33]. The prices per medication were obtained from the Royal Dutch Society of Pharmacy [34]. Costs of healthcare devices, aids and adaptations were estimated by asking retail prices from three suppliers in The Netherlands. For each product, the average price was used. All costs were expressed in 2007 Euros.

\section{Statistical methods}

Baseline characteristics were estimated for the intervention and usual care groups. The economic evaluation was performed according to the intention-to-treat principle. The incremental cost-effectiveness ratios were calculated (differences in costs divided by differences in effects between the intervention and usual care groups). Imputation of missing values was done using the Multivariate Imputation by Chained Equations algorithm [35]. The imputation model, which was used to estimate the imputed values, included the variables group randomisation, age, sex, education level, Mini-Mental State Examination, number of chronic diseases and score on the fall risk profile. According to the variables in the imputation model, imputed values were based on linear, logistic or polytomous regression estimates. Imputation of cost variables was done before multiplying volumes by cost prices. For medication, the total costs were imputed. Five imputed datasets were created. The quality of the imputations depends on the amount of missing data. When this does not exceed $50 \%$, as in our study (approximately 10\%), five imputations are enough to get valid cost estimates [36]. The analyses were done in each dataset and presented are the pooled results of the five imputed datasets as described below.

Arithmetic mean (standard deviation, SD) costs were computed for both groups. Means and differences in costs and effects were estimated in each imputed dataset and results were combined by using Rubin's rules [37]. Mean difference between groups and the associated biascorrected and accelerated confidence intervals were calcu- lated using bootstrapping techniques. Bootstrap analyses to construct bias-corrected and accelerated confidence intervals were done in each imputed dataset and results were pooled [38].

The economic evaluation involved estimating incremental cost-effectiveness ratios (ICER) of the incremental costs per avoided faller and recurrent faller. Also, an incremental costutility ratio (ICUR) was estimated for the incremental costs per QALY. ICERs and ICUR were estimated by dividing the difference in costs by the difference in effects (ICER) or utility (ICUR; intervention minus usual care) in the imputed datasets. Uncertainty around the ratios was estimated using bootstrapping techniques and graphically represented on a cost-effectiveness plane. Cost-effectiveness acceptability curves were presented to indicate the probability that the multifactorial transmural intervention was cost-effective given a ceiling ratio (i.e. maximum costs) that policymakers are willing to invest. To evaluate the influence of the missing values and their substitution by using multiple imputation techniques, we performed a sensitivity analysis. In this way, we were able to study the influence of missingness on the precision of the study results and check whether missing values were missing completely at random.

\section{Results}

Of the 2,015 persons who visited the A\&E or general practitioner after a fall, 581 were not eligible, 771 refused participation, 63 were deceased before contact and 600 were willing to participate (Fig. 1). Of the 600 persons who signed informed consent, 32 were excluded, four did not want to participate, and 347 were assigned to the low risk group leaving 217 to be randomised into the intervention $(n=106)$ and usual care groups $(n=111)$. The persons who refused to participate were more often contacted via the A\&E department $(p<0.001)$, but did not differ from participants in age or sex $(p \geq 0.08)$. Of all 217 participants included in the analyses, eight died $(3.7 \%$; seven in the usual care group, one in the intervention group) and 22 dropped out $(10.1 \%$; ten in the usual care group, 12 in the intervention group) during follow-up. Persons who dropped out in the intervention group did not differ from persons in the control group regarding age, sex, level of education, $\geq 2$ falls in the preceding year and score on the fall risk profile $(p>0.42)$.

The groups were similar at baseline with regard to potential confounding factors (Table 1). The average age was 79.0 years (SD 7.7) in the intervention group and 80.6 years (SD 7.0) in the usual care group. The percentages of women were 67 in the intervention group and 74 in the usual care group. The median utility at baseline was 0.78 [Interquartile range $0.65-0.84$ ] in both 


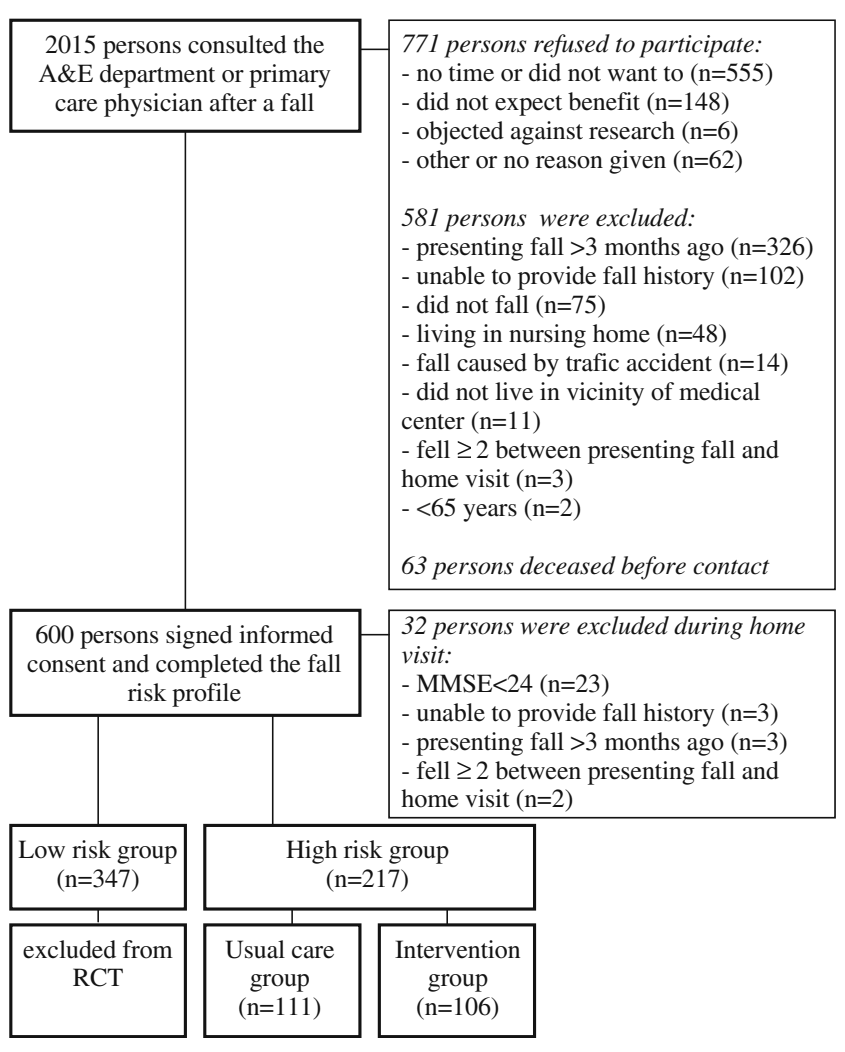

Fig. 1 Flow chart of participants included in the study

groups. Table 2 gives an overview of the recommendations given in the intervention group and the adherence to these recommendations. The numbers of fallers during 1 year of follow-up were $55(52 \%)$ and $62(56 \%)$, and the numbers of recurrent fallers were $37(35 \%)$ and $35(32 \%)$ in the intervention and usual care groups, respectively (Table 3 ). During follow-up, five persons in the intervention group and five persons in the usual care group suffered a fracture, of whom two persons in the intervention group and no persons in the usual care group had multiple fractures. In addition, the difference in QALYs gained over 1 year of follow-up between the intervention, and usual group was small and not statistically significant.

The total mean costs were Euro 7,740 (SD 9,129) in the intervention group and Euro 6,838 (SD 8,623) in the usual care group (Table 4). The intervention and usual care groups did not differ in total costs (Euro 902; 95\% CI:
$-1,534$ to 3,357$)$. Also, the mean healthcare costs and the mean patient and family costs did not differ significantly between the groups (Table 4). Figure 2 shows the costeffectiveness planes for the intervention group in comparison with the usual care group for the outcomes fallers, recurrent fallers and QALYs gained. In all three planes, the cost-effect pairs cluster around the origin, indicating neither large nor significant differences in costs and effects. The percentage of fallers was $4.0 \%$ lower in the intervention group as compared with the usual care group and the costs were Euro 902 higher, resulting in an ICER of 226. In other words, the costs per percentage decrease in fallers are 226 Euros. Since the percentage of recurrent fallers was higher in the intervention than in the usual care group, the ICER for recurrent falling was negative (ICER $=-280$ ). The acceptability curves show that the maximum probability of cost-effectiveness with respect to the proportion of fallers was obtained at a ceiling ratio of Euro 10,000 (Fig. 2). This indicates that if Euro 10,000 were invested, the probability that the intervention would reduce the percentage of fallers by $1 \%$ was 0.80 . Likewise, if Euro 300,000 were invested, the probability that the intervention would improve the quality of life (utility) by one point was only about 0.30 . Since the costs were higher and effects were smaller for the outcome recurrent fallers, the intervention was not cost-effective at any given ceiling ratio and therefore this curve was not included in Fig. 2.

To test the impact of imputation, the analyses were repeated with the 73 and 74 participants in the intervention and usual care groups, respectively, who had complete data. The total costs in the intervention group were Euro 220 lower than in the usual care group; however, this difference was not statistically significant (bootstrapped 95\% CI: $-2,754$ to 2,224). Since the percentage of fallers and recurrent fallers did not differ between the groups, the cost-effectiveness ratios clustered around the origin. ICERs were 116 for fallers, -120 for recurrent fallers and 23,044 for QALYs (data not shown).

\section{Discussion}

This study investigated the cost-effectiveness of multifactorial evaluation and treatment of fall risk factors in persons

Table 1 Baseline characteristics

${ }^{a}$ Living in a home for the elderly versus community-dwelling

\begin{tabular}{lcc}
\hline & Intervention group $(n=106)$ & Usual care group $(n=111)$ \\
\hline Age (mean (SD)) & $79.0(7.7)$ & $80.6(7.0)$ \\
Sex $(\%$ women) & 67.0 & 73.9 \\
Education $(\% \geq 11$ years of education) & 61.9 & 55.0 \\
Living situation (\% home) & 3.8 & 4.5 \\
Baseline utility (EQ-5D) & $0.78[0.65-0.84]$ & $0.78[0.65-0.84]$ \\
Falls preceding year $(\% \geq 2$ falls) & 78.6 & 75.0 \\
\hline
\end{tabular}


Table 2 Specification of recommendations and adherence in the intervention group

\begin{tabular}{|c|c|c|c|c|c|}
\hline \multirow[t]{2}{*}{ Type of recommendation } & \multicolumn{5}{|c|}{ Adhered to recommendation } \\
\hline & Total number & Yes & Alternative $^{\mathrm{a}}$ & No & Unknown \\
\hline Referrals & 176 & 101 & 25 & 25 & 25 \\
\hline Physical therapy & 80 & 47 & 11 & 11 & 11 \\
\hline Occupational therapy & 30 & 17 & 5 & 5 & 3 \\
\hline Ophthalmologist & 20 & 10 & 1 & 3 & 6 \\
\hline Cardiologist & 11 & 8 & 1 & 0 & 2 \\
\hline Other referrals & 35 & 19 & 7 & 6 & 3 \\
\hline Medication & 111 & 49 & 19 & 22 & 21 \\
\hline Initiation Calcium/vitamin D & 19 & 11 & 3 & 4 & 1 \\
\hline Discontinue benzodiazepines & 17 & 6 & 5 & 4 & 2 \\
\hline Other medication changes & 75 & 32 & 11 & 14 & 18 \\
\hline Instructions & 52 & 27 & 13 & 9 & 3 \\
\hline Risky behaviour & 8 & 4 & 1 & 3 & 0 \\
\hline Reduce alcohol intake & 10 & 4 & 3 & 2 & 1 \\
\hline Other instructions & 34 & 19 & 9 & 4 & 2 \\
\hline Mixed recommendations & 19 & 10 & 2 & 4 & 4 \\
\hline Use of compression stockings & 15 & 8 & 1 & 3 & 3 \\
\hline Other recommendations & 4 & 2 & 1 & 1 & 1 \\
\hline Total recommendations & 358 & 187 & 59 & 60 & 52 \\
\hline$\%$ of recommendations & & 52.2 & 16.5 & 16.8 & 14.5 \\
\hline
\end{tabular}

${ }^{a}$ Alternative indicates that the participant took action in response to the recommendation, but did not exactly or only partially did what was recommended (this Table has been previously published in [25])

with a high risk of recurrent falling. The intervention did not reduce the fall risk as compared with usual care during 1 year of follow-up. The average costs made from a societal perspective in persons with a high risk of recurrent falling who received the multifactorial intervention was Euro 7,740 in 1 year, which was Euro 902 higher than in the control group that received usual care.

Explanations for a lack of differences in fall risk between the two groups have been described in detail elsewhere. In short, one explanation may be a lack of contrast and second, the intervention may not be adequate in the high risk group that we selected [25]. Lack of contrast may be due to limited adherence in the intervention group and/or improved usual care and increased awareness of the fall risk in the usual care group. Although the adherence rates are within the ranges reported in previous fall prevention trials, only about half of the recommendations have been fully adhered to. Higher adherence rates might have led to fewer falls, but also to higher costs. Therefore, it is impossible to judge whether better adherence would have improved the cost-effectiveness of this intervention.

The mean costs of participants who received the intervention were somewhat, but not statistically significant, higher than in participants who received usual care. Closer inspection of the costs per category reveals that medication costs were higher in the intervention group and these participants also tended to have higher costs of allied health care. Revision of medication was a facet of the

Table 3 Clinical outcomes at 12 months and incremental cost-effectiveness ratios

\begin{tabular}{llllll}
\hline & Intervention group & Usual care group & Difference & 95\% CI & ICER \\
\hline$\%$ fallers & 52 & 56 & -4.0 & -17 to 9 & 226 \\
\% recurrent fallers & 31 & 28 & 3.2 & -9 to 15 & -280 \\
Mean (SD) QALY & $0.76(0.11)$ & $0.76(0.14)$ & -0.004 & -0.021 to 0.029 & $-232,533^{\text {a }}$ \\
\hline
\end{tabular}

Presented are the pooled mean differences and $95 \%$ confidence intervals in the clinical outcome measures and incremental cost-effectiveness ratios (ICER)

${ }^{\mathrm{a}}$ Incremental cost-utility ratio 
Table 4 Mean health care, patient and family, and total costs in Euros in the intervention and usual care groups

\begin{tabular}{|c|c|c|c|}
\hline & Intervention $(n=106)$ & Usual care $(n=111)$ & Bootstrap 95\% CI \\
\hline Healthcare costs & 5995 (8399) & $4858(7606)$ & -1091 to 3371 \\
\hline - General practitioner ${ }^{\mathrm{a}}$ & $167(242)$ & $136(144)$ & -12 to 101 \\
\hline - Hospital-related ${ }^{\mathrm{b}}$ & $2195(4755)$ & $1720(3950)$ & -672 to 1741 \\
\hline - Paramedic and alternative medicine ${ }^{c}$ & $894(1067)$ & $644(861)$ & -8 to 526 \\
\hline - Formal care ${ }^{\mathrm{d}}$ & $1369(4338)$ & $1614(5827)$ & -1945 to 980 \\
\hline - Medication ${ }^{\mathrm{e}}$ & $1370(4870)$ & $745(685)$ & 64 to 2655 \\
\hline Patient and family costs & $404(695)$ & 409 (1079) & -339 to 207 \\
\hline - Informal care ${ }^{\mathrm{f}}$ & $313(682)$ & $310(1080)$ & -298 to 217 \\
\hline - Other costs ${ }^{\mathrm{g}}$ & $90(111)$ & $99(91)$ & -37 to 23 \\
\hline Costs in other sectors & $1332(2203)$ & $1566(3285)$ & -1133 to 445 \\
\hline - Transportation ${ }^{\mathrm{h}}$ & $413(1202)$ & $739(2623)$ & -1137 to 241 \\
\hline - Healthcare devices, aids and adaptations $\mathrm{s}^{\mathrm{i}}$ & 843 (1543) & 759 (1613) & -355 to 538 \\
\hline Total costs & 7740 (9129) & $6838(8623)$ & -1534 to 3357 \\
\hline
\end{tabular}

Presented are pooled means (SD) and the bias-corrected and accelerated bootstrapped $95 \%$ confidence intervals in Euros

${ }^{a}$ General practitioner consultations (including telephone consultations and home visits)

${ }^{\mathrm{b}}$ Specialized physician consultations (e.g. ophthalmologist, internal physician, geriatrician) emergency department consultations, hospital admittance and surgeries

${ }^{\mathrm{c}}$ Consultations of physiotherapist, occupational therapist and other therapists including alternative medicine

${ }^{\mathrm{d}}$ Home care (i.e. housekeeping, personal care, meal preparation, preparation and administration of medications and wound care), day care and admittance to nursing home or home for the elderly

${ }^{\mathrm{e}}$ Over the counter and prescribed drugs

${ }^{\mathrm{f}}$ Care received from family, neighbours and friends

${ }^{\mathrm{g}}$ Pedicure and exercise programs (other than physiotherapy)

${ }^{\text {h}}$ Wheel chair, platform scooter, handicapped parking placard and bicycle

${ }^{i}$ Rollator, crutches, walking stick, Zimmer frame, orthopaedic shoes, brace/splint, compression stocking, hip protector, incontinence products, personal alarm, glasses, hearing aids, handrails, removing thresholds, smoothing surfaces, ramp, stair lift, replacing bathtub by shower, shower seat, (anti-slip) floor covering, electric door opener, high toilet, toilet arm rests, toilet chair, bath seat/lift, bath mat, raised chair, rise chair, working chair, bed raisers, height adjustable bed and bed triangle

intervention: $24 \%$ of the participants in the intervention group were recommended to reduce or stop some medications while $33 \%$ of the participants were recommended to start using certain medications. The costs per unit of the stopped medications (mostly psychopharmaca) were lower than the costs per unit of the started medications (mostly osteoporosis medication). This, in combination with the net rise in number of medications, may explain the higher costs in the intervention group. The higher costs of allied health care were anticipated because $81 \%$ of the participants in the intervention group were referred to the physiotherapist and/ or occupational therapist. However, we also anticipated higher costs for healthcare devices, aids and adaptations. Lack of differences in costs between the two groups may be because the intervention group did not adhere to the recommendations given by the occupational therapist regarding aids and adaptations and/or the usual care group also acquired aids and adaptations. The latter explanation is likely, since in The Netherlands, devices such as walking aids, shower seats and platform scooters are easily accessible via health insurances and municipalities. Also, some participants from the usual care group declared that completing the questionnaires notified them that aids and adaptations may be helpful for them.

Two previous studies have evaluated the costeffectiveness of multifactorial fall prevention programs. Both our study and a recently published study which was conducted in Maastricht, The Netherlands did not show a difference in either costs or effects between the intervention and usual care groups [7]. The total costs in our study were somewhat higher than in the Maastricht study. However, in the Maastricht study all patients who consulted the A\&E department after a fall were considered at high risk of falling, while we screened these patients to select those with a high risk of recurrent falling. Consequently, our sample was older and had a higher fall risk. In addition, the intervention participants in our study received more recommendations per person and the compliance rate was higher [24]. Finally, they expressed costs in 2004 Euros, whereas we expressed costs in 2007 Euros $(1.0452 \%$ price 


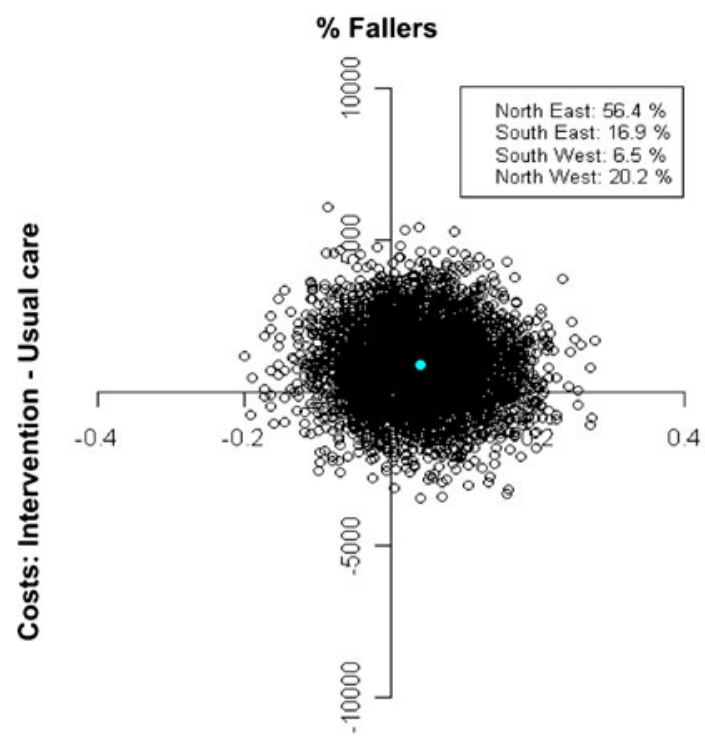

Effects: Intervention - Usual care

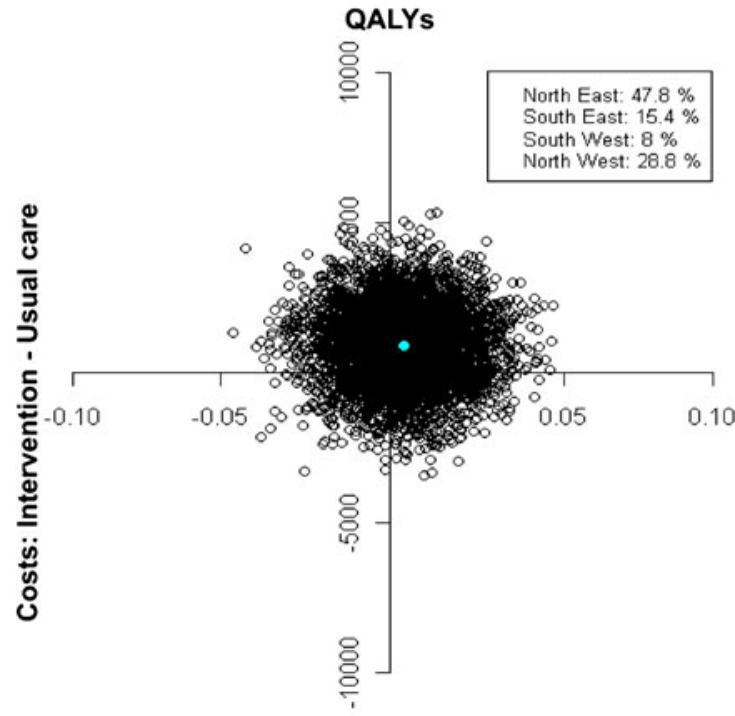

Effects: Intervention - Usual care

Fig. 2 Cost-effectiveness planes and acceptability curves for the multifactorial evaluation and treatment of fall risk factors in comparison with usual care. Top left: cost-effectiveness plane differences in percentage of fallers. Top right: cost-effectiveness plane for differences in percentage of recurrent fallers. Bottom left: costeffectiveness plane for differences in utility (QALY) after 1 year. Bottom right: acceptability curves presenting the probability of the intervention being cost-effective as compared with usual care at various ceiling ratios of costs, presented for fallers (solid line) and

index from 2004 to 2007). In 1996, a similar study was conducted in New Haven, CT [23]. In this US study, the multifactorial targeted prevention program reduced the fall rate by almost $50 \%$ and the costs by $26 \%$ in participants with a high fall risk. However, two differences should be emphasized: first, the US study did not include patient and family costs, and second, usual care more often includes home

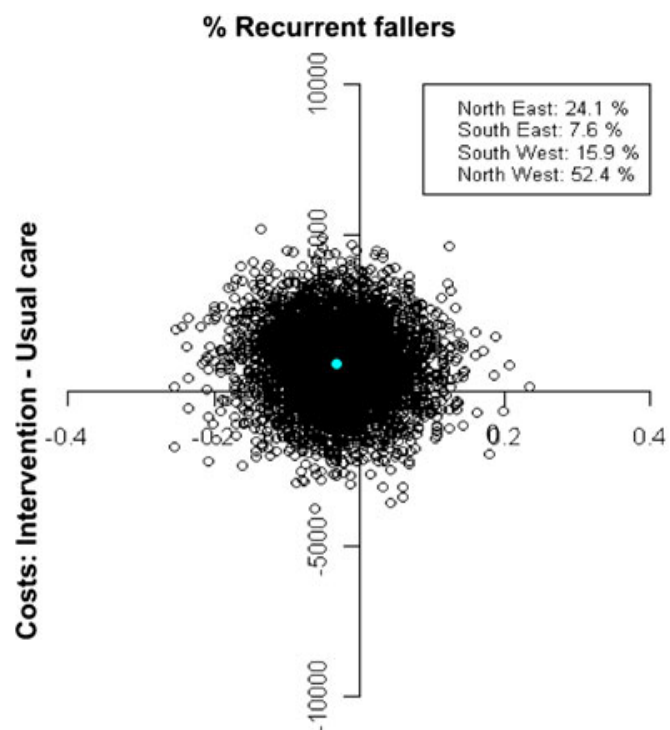

Effects: Intervention - Usual care

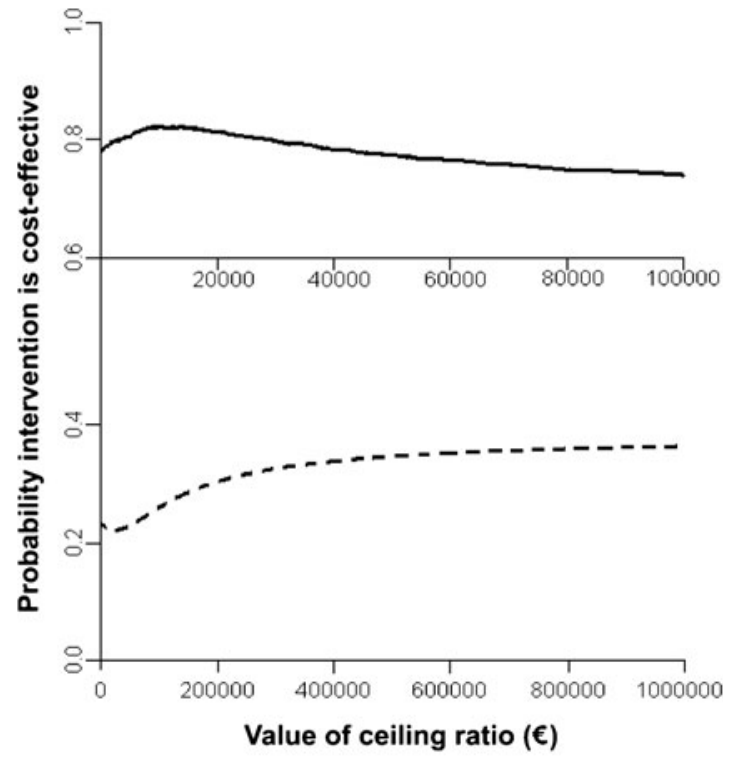

QALYs (dashed line). For a detailed explanation of the CostEffectiveness Acceptability Curves (CEAC), we would like to refer readers to [40]). The panels in the cost-effectiveness planes display the percentages of estimated ratios per quadrant of the plane. North East quadrant intervention is more effective and more expensive, South East quadrant intervention is more effective and less expensive, South West quadrant intervention is less effective and less expensive, North West quadrant intervention is less effective and more expensive

modifications in The Netherlands than in the US. In The Netherlands, municipalities are responsible for their inhabitants to live as safely and independently as possible in their own environment and financial resources are available to improve the home environment for people who are disabled.

In the literature, it has been hypothesized that the costeffectiveness of multifactorial evaluation and treatment of 
fall risk factors may be improved by selecting persons with a high risk of falling [22]. The current results do not support this hypothesis. Over the past few years, many geriatricians have initiated fall clinics with multifactorial preventive programs in The Netherlands. However, both the current study and the Maastricht study showed that this approach reduces neither the fall rate nor the costs among high-risk patients and is thus not superior to usual care in The Netherlands. It is recommended that multifactorial evaluation and treatment of fall risk factors in older persons with a high fall risk should not be implemented in The Netherlands. Since healthcare costs and the content of usual care differ across countries, generalizing the current results to other countries may not be relevant.

This study included both community-dwelling persons and residential home residents. In The Netherlands, persons living in a residential home, usually require either some assistance for (instrumental) activities of daily living or services to prevent social isolation, but still have a high level of autonomy. The assistance needed is limited to fixed times of the day, e.g. help to get out of bed or to take medication. Additional frequent (non-)structural help, e.g. assistance to go the toilet or get a drink, or low level of autonomy classifies for nursing home admittance. The proportion of persons living in a residential home in this study was too low to analyse whether the cost-effectiveness of the current intervention differs between communitydwelling and residential home participants.

Some limitations of this study need to be pointed out. First, the main aim of this study was to study the effectiveness of the intervention that is why the power calculation was based on a falls reduction rather than QALYs or costs. Power calculations based on QALYs or costs would have been difficult given the absence of information in the literature on potential effects of the intervention on these outcomes. Second, only 150 persons completed all three cost-evaluation questionnaires. Participants who did not return all questionnaires were older and frailer, and it is likely that the costs among these persons are higher. However, the proportions of missing questionnaires did not differ between the intervention and usual care groups. The total mean costs per group may be underestimated, but not the difference in costs. Third, the medication costs were estimated based on the assumptions described in the method. These assumptions introduce uncertainty in the estimation of the total costs and consequently the incremental cost-effectiveness ratios. However, the same assumptions were used in both groups. Furthermore, repeating the analyses without the medication costs resulted in a smaller difference in the total costs between the two groups, and thus a smaller ICER. Fourth, imputation of missing values introduces extra uncertainty in the estimation of the effects. However, sensitivity analyses among persons with complete data revealed that the impact of imputation did not alter the results. Fifth, we did not measure the costs in the low risk group. Thus, no conclusions can be drawn with respect to the costs or cost-effectiveness of the screening for risk of recurrent falling. In addition, we also did not measure costs at baseline because at that time the intervention had not started yet. We measured costs after randomization. In any economic evaluation, differences at baseline might explain differences indentified during follow-up. However, our randomization was successful, and no relevant baseline differences were observed. Consequently, it is very unlikely that there would have been any baseline differences in costs. Finally, recent literature suggests that statistical analysis in falls studies that allow for analysing all falls rather than a fall are more sensitive and might have picked up a difference between the intervention and usual care group that we did not find with the outcome measures "faller" and "recurrent faller" [39]. However, because of ethical considerations, when a person from the usual care group fell twice or more within 6 months during follow-up (recurrent faller), we informed his/her GP of the person's increased fall risk and advised the GP to initiate preventive measures. This may have affected the fall risk and number of falls during the remainder of the follow-up. Therefore, we did not present the number of falls as a primary outcome in this study.

In conclusion, multifactorial evaluation and treatment of persons with a high risk of recurrent falling does not seem cost-effective compared to usual care.

\section{Conflicts of interest None.}

Open Access This article is distributed under the terms of the Creative Commons Attribution Noncommercial License which permits any noncommercial use, distribution, and reproduction in any medium, provided the original author(s) and source are credited.

\section{References}

1. Murray CJ, Lopez AD (1996) Global and regional descriptive epidemiology of disability: incidence, prevalence, health expectancies and years lived with disability. In: Murray CJ, Lopez AD (eds) The global burden of disease. Harvard School of Public Health, Boston, pp 201-246

2. Nevitt MC, Cummings SR, Kidd S, Black D (1989) Risk factors for recurrent nonsyncopal falls. A prospective study. JAMA 261:2663-2668

3. Tinetti ME, Doucette J, Claus E, Marottoli R (1995) Risk factors for serious injury during falls by older persons in the community. J Am Geriatr Soc 43:1214-1221

4. Tromp AM, Smit JH, Deeg DJ, Bouter LM, Lips P (1998) Predictors for falls and fractures in the Longitudinal Aging Study Amsterdam. J Bone Miner Res 13:1932-1939 
5. Graham HJ, Firth J (1992) Home accidents in older people: role of primary health care team. BMJ 305:30-32

6. Stel VS, Smit JH, Pluijm SM, Lips P (2004) Consequences of falling in older men and women and risk factors for health service use and functional decline. Age Ageing 33:58-65

7. Hendriks MR, Evers SM, Bleijlevens MH, van Haastregt JC, Crebolder HF, van Eijk JT (2008) Cost-effectiveness of a multidisciplinary fall prevention program in community-dwelling elderly people: A randomized controlled trial (ISRCTN 64716113). Int J Technol Assess Health Care 24:193-202

8. Close JC, Hooper R, Glucksman E, Jackson SH, Swift CG (2003) Predictors of falls in a high risk population: results from the prevention of falls in the elderly trial (PROFET). Emerg Med J 20:421-425

9. Hendriks MR, Bleijlevens MH, van Haastregt JC, Crebolder HF, Diederiks JP, Evers SM, Mulder WJ, Kempen GI, van Rossum E, Ruijgrok JM, Stalenhoef PA, van Eijk JT (2008) Lack of effectiveness of a multidisciplinary fall-prevention program in elderly people at risk: a randomized, controlled trial. J Am Geriatr Soc 56:1390-1397

10. Davison J, Bond J, Dawson P, Steen IN, Kenny RA (2005) Patients with recurrent falls attending Accident \& Emergency benefit from multifactorial intervention-a randomised controlled trial. Age Ageing 34:162-168

11. Hogan DB, MacDonald FA, Betts J, Bricker S, Ebly EM, Delarue B, Fung TS, Harbidge C, Hunter M, Maxwell CJ, Metcalf B (2001) A randomized controlled trial of a community-based consultation service to prevent falls. CMAJ 165:537-543

12. Lightbody E, Watkins C, Leathley M, Sharma A, Lye M (2002) Evaluation of a nurse-led falls prevention programme versus usual care: a randomized controlled trial. Age Ageing 31:203-210

13. Lord SR, Tiedemann A, Chapman K, Munro B, Murray SM, Gerontology M, Ther GR, Sherrington C (2005) The effect of an individualized fall prevention program on fall risk and falls in older people: a randomized, controlled trial. J Am Geriatr Soc 53:1296-1304

14. McMurdo ME, Millar AM, Daly F (2000) A randomized controlled trial of fall prevention strategies in old peoples' homes. Gerontology 46:83-87

15. Tinetti ME, Baker DI, McAvay G, Claus EB, Garrett P, Gottschalk M, Koch ML, Trainor K, Horwitz RI (1994) A multifactorial intervention to reduce the risk of falling among elderly people living in the community. N Engl J Med 331:821-827

16. van Haastregt JC, Diederiks JP, van Rossum E, de Witte LP, Voorhoeve PM, Crebolder HF (2000) Effects of a programme of multifactorial home visits on falls and mobility impairments in elderly people at risk: randomised controlled trial. BMJ 321:994-998

17. Chang JT, Morton SC, Rubenstein LZ, Mojica WA, Maglione M, Suttorp MJ, Roth EA, Shekelle PG (2004) Interventions for the prevention of falls in older adults: systematic review and metaanalysis of randomised clinical trials. BMJ 328:680

18. Gates S, Fisher JD, Cooke MW, Carter YH, Lamb SE (2008) Multifactorial assessment and targeted intervention for preventing falls and injuries among older people in community and emergency care settings: systematic review and meta-analysis. BMJ 336:130-133

19. Gillespie LD, Robertson MC, Gillespie WJ, Lamb SE, Gates S, Cumming RG, Rowe BH (2009) Interventions for preventing falls in older people living in the community. Cochrane.Database Syst. Rev.CD007146

20. Kwaliteitsinstituut voor de Gezondheidszorg CBO (2004) Richtlijn Preventie van valincidenten bij ouderen [Guideline Prevention of fall incidents in older persons]. Van Zuiden Communications B.V., Alphen aan den Rijn
21. American Geriatrics Society, British Geriatrics Society and American Academy of Orthopaedic Surgeons Panel on Falls Prevention (2001) Guideline for the prevention of falls in older persons. J Am Geriatr Soc 49:664-672

22. Gardner MM, Robertson MC, Campbell AJ (2000) Exercise in preventing falls and fall related injuries in older people: a review of randomised controlled trials. Br J Sports Med 34:7-17

23. Rizzo JA, Baker DI, McAvay G, Tinetti ME (1996) The costeffectiveness of a multifactorial targeted prevention program for falls among community elderly persons. Med Care 34:954-969

24. Bleijlevens MH, Hendriks MM, van Haastregt JC, van Rossum E, Kempen GI, Diederiks JP, Crebolder HF, van Eijk JT (2008) Process factors explaining the ineffectiveness of a multidisciplinary fall prevention programme: a process evaluation. BMC Public Health 8:332

25. de Vries OJ, Peeters GM, Elders PJ, Muller M, Knol DL, Danner SA, Bouter LM, Lips P (2010) A multifactorial intervention to reduce falls in older people at high risk of recurrent falls; a randomized controlled trial. Arch Intern Med 170:1110-1117

26. Peeters GM, de Vries OJ, Elders PJ, Pluijm SM, Bouter LM, Lips P (2007) Prevention of fall incidents in patients with a high risk of falling: design of a randomised controlled trial with an economic evaluation of the effect of multidisciplinary transmural care. BMC Geriatr 7:15

27. Pluijm SM, Smit JH, Tromp EA, Stel VS, Deeg DJ, Bouter LM, Lips P (2006) A risk profile for identifying community-dwelling elderly with a high risk of recurrent falling: results of a 3-year prospective study. Osteoporos Int 17:417-425

28. Peeters GM, Pluijm SM, van Schoor NM, Elders PJ, Bouter LM, Lips P (2010) Validation of the LASA fall risk profile for recurrent falling in older recent fallers. J Clin Epidemiol 63:1242-1248

29. Kellogg International Work Group on the Prevention of Falls by the Elderly (1987) The prevention of falls in later life. Dan Med Bull 34(Suppl 4):1-24

30. Brooks R (1996) EuroQol: the current state of play. Health Policy 37:53-72

31. Lamers LM, Stalmeier PF, McDonnell J, Krabbe PF, van Busschbach JJ (2005) Measuring the quality of life in economic evaluations: the Dutch EQ-5D tariff. Ned Tijdschr Geneeskd 149:1574-1578

32. Oostenbrink JB, Bouwmans CAM, Koopmanschap MA, Rutten FFH (2004) Handleiding voor kostenonderzoek. Methoden en richtlijnprijzen voor economische evaluaties in de gezondheidszorg [Handbook for cost studies, methods and guidelines for economic evaluation in health care]. Health Care Insurance Council, The Hague

33. van Loenen A (2008) Farmacotherapeutisch Kompas: medisch farmaceutische voorlichting. College voor Zorgverzekeringen, Diemen, the Netherlands

34. Z-index (2006) G-standaard. Z-index BV, The Hague

35. van Buuren S, Oudshoorn K (1999) Technical report. TNO Quality of Life, Leiden, the Netherlands

36. Schafer JL (1999) Multiple imputation: a primer. Stat Methods Med Res 8:3-15

37. Rubin DB (1987) Multiple imputation for nonresponse in surveys. Wiley, New York

38. Burton A, Billingham LJ, Bryan S (2007) Cost-effectiveness in clinical trials: using multiple imputation to deal with incomplete cost data. Clin Trials 4:154-161

39. Gill DP, Zou GY, Jones GR, Speechley M (2009) Comparison of regression models for the analysis of fall risk factors in older veterans. Ann Epidemiol 19(8):523-530

40. Fenwick E, O’Brian BJ, Briggs A (2004) Cost-effectiveness acceptability curves - facts, fallacies, and frequently asked questions. Health Economics 13:404-415 